Article

\title{
Protect Me from What I Want: Understanding Excessive Polluting Behavior and the Willingness to Act
}

\author{
Ragna Benedikta Garðarsdóttir ${ }^{1}$ (D), Hrund Ólöf Andradóttir ${ }^{2, *}$ and Throstur Thorsteinsson ${ }^{3}$ (D) \\ 1 Faculty of Psychology, School of Health Sciences, University of Iceland, Nyi Gardur, 107 Reykjavik, Iceland; \\ rbg@hi.is \\ 2 Faculty of Civil and Environmental Engineering, School of Engineering and Natural Sciences, \\ University of Iceland, 107 Reykjavik, Iceland \\ 3 Faculty of Earth Sciences and Environment and Natural Resources, School of Engineering and Natural \\ Sciences, University of Iceland, 101 Reykjavik, Iceland; ThrosturTh@hi.is \\ * Correspondence: hrund@hi.is; Tel.: +354-864-0634
}

Received: 26 June 2020; Accepted: 19 July 2020; Published: 21 July 2020

\begin{abstract}
Many environmental problems stem from unsustainable human consumption. Accordingly, many studies have focused on the barriers to pro-environmental behavior. The inability or unwillingness to act is partially related to personal values as well as the psychological distance between individual actions and the resulting pollution, which is often perceived as abstract or intangible. In contrast, fireworks produce imminent, undeniable air pollution. The goal of this research was to advance the knowledge on the awareness-value-behavior gap by studying public fireworks consumption and the willingness to act against firework pollution. A nationally representative survey was conducted after the extremely polluting 2017/18 New Year's Eve in Iceland (European hourly record in fine particulate matter: $3014 \mu \mathrm{g} / \mathrm{m}^{3}$ ). Our results demonstrate that, after controlling for the awareness of harmful pollution, hedonic motives predict the purchasing of fireworks and the opposition to mitigating action. Noticing public warnings regarding fireworks pollution did not significantly relate to the purchase behavior. The awareness of the harmful effects of firework pollution was, however, the largest predictor of the support for mitigating action. Despite reporting the pleasure derived from fireworks, $57 \%$ of the sample favored stricter governmental regulation, and $27 \%$ favored banning the public use of fireworks in order to "protect them from what they want".
\end{abstract}

Keywords: firework pollution; pro-environmental behavior; hedonic motives; psychological distance; environmental awareness

\section{Introduction}

It is well established that the leading cause of the current environmental problems is human behavior [1]. Our consumer habits have not only caused a climate crisis but have also led to the loss of biodiversity and the pollution of water, land, and air [2,3]. Therefore, psychologists have increasingly been called upon to explain what drives such unsustainable consumer behavior and how to promote more ecologically friendly actions. Most of that research has focused on climate change or individual acts such as recycling, but very few have tried to understand polluting behavior. Pollution, by its nature, has consequences for both the environment and health. Fireworks are created purely for hedonic purposes. They are purposefully visible and loud and provide a short-lived, immediate gain. They are, however, sources of extreme pollution, which is damaging to the environment and to human health. Therefore, the public use of fireworks is a fascinating topic for interdisciplinary research in psychology and the environmental sciences. 
Research on pollution is scarce in the field of psychology, and that which does exist focuses on emissions and urban pollution. Self-inflicted pollution, such as that caused by fireworks, differs from the pollution that people are daily exposed to in big cities. Urban pollution is the culmination of traffic and industry, both of which are the result of modern lifestyles. The cumulative and infrastructural nature of such pollution means that people may fail to attribute it to their individual actions, which in turn means they fail to, or are unable to, take appropriate action [4]. Firework pollution differs from that since it is not a "necessary evil" resulting from modern lifestyles. It is rather an extremely polluting, psychologically proximal and inherently hedonic activity. The goal of this study was to assess the psychological factors influencing the public use of fireworks and people's willingness to act to mitigate firework pollution. We take advantage of the unique situation of extreme public firework usage in Iceland and the fact that fireworks are predominantly marketed as a charitable purchase and that their purchase can be construed as an altruistic act.

\subsection{Psychological Factors Influencing Polluting Behavior}

The psychological literature on environmental behavior has largely focused on how internal factors such as values, motives, attitudes, knowledge, and perception influence pro-environmental behavior. This research has, for example, demonstrated that neither pro-environmental knowledge nor the awareness of environmental harm necessarily translate into pro-environmental behavior [4]. People rate their concern for the environment higher than they rate their willingness to act [5]. The reasons for this gap between the awareness of negative consequences, on the one hand, and willingness to act, on the other, can be structural, societal, as well as psychological [6-9]. The psychological reasons-or barriers, as they are called-are a collection of cognitions, values, and motives which hinder people's willingness or ability to adopt lifestyle changes.

Values are defined as "trans-situational goals, varying in importance, that serve as guiding principles in the life of a person or group and can help to explain individual decision making, attitudes, and behaviour" [10] (p. 664). The essential content of a value is the motivational goal that it expresses. Some values are compatible with each other in that they are motivated by similar needs, while others are in conflict. People can hold different values, but only the salient value may motivate behavior. The more important a value is to a person, the greater the influence it may have on behavior [10]. However, this relation is dependent on specific situations to activate these values [11]. Further, while values can motivate behavior, normative factors might obscure these relations [12]. Various taxonomies for the ordering of values exist, but within the environmental literature the most widely used is deGroot \& Steg's distinction between egoistic, altruistic, and biospheric values [13], which act as guiding principles and motivate action. According to their theory, egoistic values contain self-focused and hedonic motives (i.e., pleasure or comfort-seeking) and are opposite to biospheric (i.e., environmentally focused) or altruistic (i.e., others-focused) values $[10,13,14]$. Of these, the egoistic values tend to be associated with less concern about environmental issues, in particular with regard to climate change [13], because they value immediate gains which conflict with the long-term collective interests of the environment. On the contrary, altruistic values tend to be positively related to pro-environmental behavior, because they focus on the collective interest and are driven by the motivational goals such as social justice and helpfulness. [13-15].

Along with egoistic values, gender, education, and political orientation are consistently found to associate with environmental behavior and the willingness to act on environmental issues. Men and those who are conservative or right-wing, less educated, and older are more likely to downplay environmental risks and oppose mitigating action [16-20].

Another barrier to people's ability to engage in pro-environmental behavior is psychological distance [21]. Many environmental problems are perceived to be abstract, unlikely, and both temporally and geographically distant, and therefore people discount them as threats [22]. The same is true for health risks. People often view risks to health as psychologically distant, assuming that they will happen to other people in other places in the future [23]. According to this viewpoint, humans are 
ill-equipped to act against intangible or distant threats because our senses evolved to detect sudden and obvious threats. It has been claimed that "Without a tangible sensory signal and attendant emotional jolt, these problems feel psychologically distant and do little to move us to action" [6] (p. 276).

\subsection{Public Engagement in Fireworks}

Fireworks provide both an emotional jolt and sensory signals. They are visible, loud, and immediately polluting and are not necessary for human survival. Therefore, the principles that apply to urban pollution or climate change may or may not apply to firework pollution, which calls for research on public engagement in this area. A distinction must be made between public engagement in fireworks and municipal or local firework displays. The former consists in the unlimited or partially regulated marketing and selling of fireworks to the general public who may purchase and ignite unlimited amounts of fireworks on designated time periods. The latter consists in controlled fireworks displays organized by local municipalities. The focus of this paper is on the former, public use, as it poses an interesting conflict between individual behavior, awareness, values, and societal norms.

In the past 25 years, the scientific literature has demonstrated that a widespread public detonation of fireworks repeatedly generates large-scale exceedances of national air quality standards [24,25]. The hourly concentration of fine particulate matter $\left(\mathrm{PM}_{2.5}\right)$ can become hundredfold higher than the 24-hour ambient air quality standard, indicating that even the healthy would experience acute discomfort [26]. The fine particulates, rich in metal and Poly Aromatic Hydrocarbons (PAHs), were found to pose risks to human health [27]. Positive associations existed between firework-events, $\mathrm{PM}_{10}$ concentrations, and daily mortality in the Netherlands [28]. In contrast, localized firework displays organized by municipalities increased $\mathrm{PM}_{2.5}$ pollution only by a fraction (15\%) of national air quality standards [29].

While the reasons for public engagement in fireworks may vary somewhat from country to country, the common function of fireworks is to arise sensory enjoyment and thrill. As such, it is a predominantly hedonic activity. This is particularly true of New Year's Eve fireworks celebrations in Northern Europe, which were publicly adopted after World War II and have neither a religious nor symbolic meaning. An interesting example of such celebrations takes place in Reykjavík, the capital of the island nation of Iceland, in North Atlantic. This small community (217 thousand inhabitants) set a European pollution record during the 2017/2018 New Year's Eve celebrations ( $3014 \mu \mathrm{g} / \mathrm{m}^{3}$ hourly $\mathrm{PM}_{2.5}$ [ [26]. The corresponding $\mathrm{PM}_{10}$ vastly exceeded the values achieved during firework celebrations in much larger Asian cities. As Figure 1 shows, the level of pollution in tiny Reykjavik exceeded that of New Delhi, where 18.7 million people live, reflecting the magnitude of public engagement in fireworks in the capital area. The smoke was so thick it mimicked the experience of driving through a volcanic ash cloud and led to emergency room visits because of severe breathing difficulties [26,30].

No less interesting, for the purpose of this study, is the fact that selling fireworks is the single most important funding source of Search and Rescue (Ice-SAR), a non-governmental volunteer organization in Iceland. It is important to stress the vital role of Ice-SAR for the inhabitants of a remote island that regularly experiences extreme weather and natural hazards such as volcanic eruptions, earthquakes, avalanches, and landslides. There is a strong social norm in Iceland to buy fireworks from Ice-SAR. Stakeholders have been reluctant to adopt actions that limit firework sales because Ice-SAR does not have alternative sources of funding that could match the income from fireworks [26]. Icelanders' use of fireworks thus presents an interesting conflict. People may claim or believe that they are motivated by altruistic and charitable values by funding Ice-SAR, but since such altruistic values are in opposition to egoistic values [10], both cannot simultaneously guide behavior. This raises the question of whether the behavior is motivated by hedonism or altruism. 


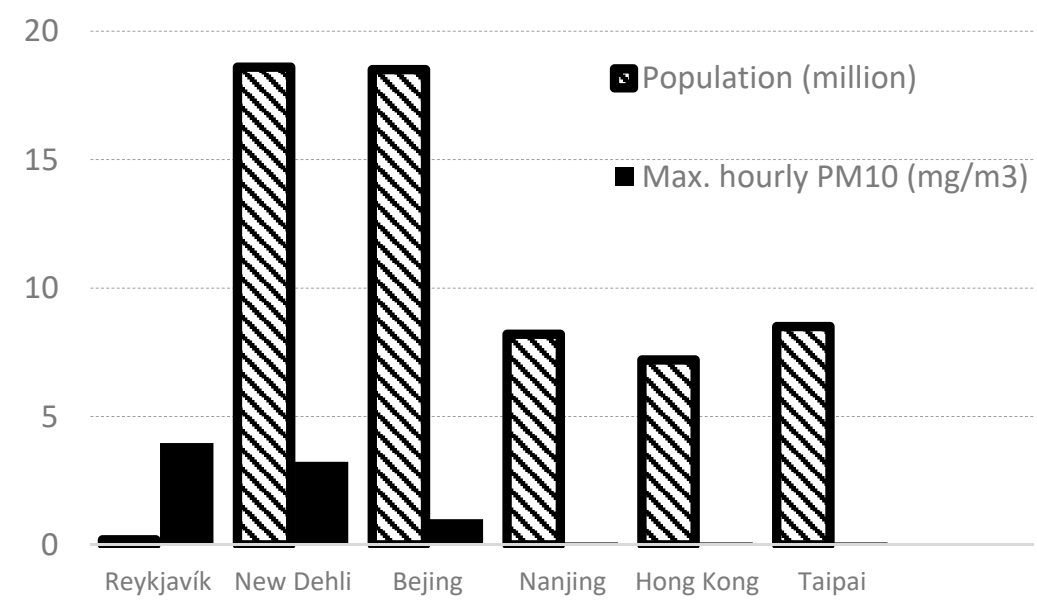

Figure 1. Hourly maximum $\mathrm{PM}_{10}$ pollution during New Year's Eve firework celebrations (Data origins: [26,31,32]; Statistics of individual countries).

\subsection{Firework Mitigation Actions}

China, the inventor and largest manufacturer and supplier of fireworks, has a long history and experience in mitigating firework pollution. Governmental top-down approaches can be classified as "restrictions" or a "full ban" of public use. A review of these efforts suggests that time and space restrictions were not able to maintain air pollution at average levels during Chinese New Year Celebrations [32]. This success was, however, achieved in cities in Southern China (e.g., Hong Kong, Figure 1), by replacing the public use of fireworks with short, controlled offshore firework displays, and then with light displays on major city buildings. Cultural factors play a role in the public acceptance of banning fireworks, and, as such, a series of bottom-up approaches with the collaboration of local media and the research community need to be complemented with top-down approaches [32,33]. Otherwise, a thriving illegal imports and black market may develop [34]. Europe has adopted the restrictions approach by limiting the types of fireworks available to the public, setting time and space restrictions, and limiting the use of harmful substances such as lead [35]. In Iceland, historically, the public has had access to larger and more polluting fireworks than those of many neighboring countries. This distinction has been used to promote the country as a travel destination for New Year's Eve for foreign tourists. The governmental mitigation actions have been limited to official warnings to the public if the pollution is expected to exceed national health safety limits [26]. To the authors' knowledge, no research to date has addressed the public willingness to act in relation to self-inflicted, imminent, extreme pollution.

\subsection{Research Hypotheses Development}

We know from previous research that knowledge or awareness alone is not sufficient to change one's behavior and that pro-environmental values do not necessarily translate into pro-environmental action. We also know that egoistic values, which contain hedonic and self-focused motives, are rarely associated with pro-environmental behavior or the willingness to accept mitigating action, but that altruistic values are. Further, rather than being a reflection of stable individual properties, different values motivate different actions when the values are salient and the action is seen as the norm. In Iceland, the predominant norm is the charitable purchase of fireworks en masse, resulting in unprecedented levels of pollution (Figure 1). We believe this results in a value conflict for the consumers, who, pressured to support a good cause, proceed to purchase and ignite fireworks, which they enjoy despite being aware of their polluting nature. This is an example of the socially conscious consumption of a harmful product where the social benefits and hedonic rewards, on the one hand, and the environmental and health damage, on the other, are at odds. 
We draw from research on the psychology of climate change and apply psychological concepts to understand why individuals undertake an extremely polluting behavior-i.e., detonating fireworks - next to their homes. In addition, we draw from fireworks literature and governmental successes and failures, and consider three different sets of governmental top-down mitigation strategies. Based on this information, we propose the following hypotheses:

Hypothesis 1 (H1). Hedonic motives (enjoyment of firing and watching fireworks) are positively related to purchasing behavior and are a stronger predictor of purchasing behavior than the awareness of the health risk of firework pollution.

Hypothesis 2 (H2). Hedonic motives (enjoyment of firing and watching fireworks) are negatively related to the acceptance of a general ban of fireworks (Hypothesis 2a), stricter regulations (Hypothesis $2 b$ ), and the intention to buy fewer fireworks (Hypothesis 2c), after controlling for background and awareness of the health risk of firework pollution.

Hypothesis 3 (H3). Hedonic motives hinder the willingness to accept mitigating action, i.e., that hedonic motives moderate the association between the awareness of the health risk of firework pollution and the willingness to accept a general ban on fireworks (Hypothesis 3a), stricter regulations (Hypothesis 3b), and the intention to heed warnings and buy fewer fireworks (Hypothesis 3c), after controlling for background. Hypotheses 1-3 address the awareness-behavior gap and previous research on egoistic values being negatively associated with pro-environmental behavior and the willingness to act.

Finally, to address the value conflict inherent in purchasing fireworks from Ice-SAR at a premium price to obtain personal short-lived entertainment, thereby funding an undeniably altruistic association:

Hypothesis 4 (H4). Charitable motives (purchasing from Ice-SAR) are a weaker predictor of purchasing behavior than hedonic motives (enjoying firing and watching fireworks). We believe that hedonism is the salient value, which people justify via socially conscious consumption.

A control for age, gender, political orientation, and education is applied in all hypotheses, as they are consistently found to associate with environmental behavior.

\section{Methods}

\subsection{Participants and Procedure}

An online survey was sent out to an internet panel of 1800 people from 12-30 May 2018. Thereof $838(46.5 \%)$ responded to the survey. The panel was developed by the Social Science Research Institute at the University of Iceland (SSRI) and was nationally representative, continuously updated, and quality checked. Furthermore, the panelists were volunteers whose data was anonymously stored at the SSRI and they were free to withdraw from participation in the panel at any time or refuse to participate in particular surveys. Our respondents were 18 years or older, and men (49.5\%) and women (50.5\%) were almost equally represented. Participants recorded their age in brackets: 18 -25-year-old $(13.4 \%)$, 26-35 (18.7\%), 36-45 (17.5\%), 46-55 (17.2\%), 56-65 (15.8\%), 66-75 (9.6\%), and 76 or older $(7.8 \%)$. Other demographics-domicile, education, profession, marital status, family status, individual income, family income, and political aspirations-were also recorded (available upon request). Responses were incentivized by a lottery with a chance to win a voucher worth USD 80. Ahead of responding, participants were assured of their anonymity, their right to withdraw from the study, and their right to refuse to answer particular questions. The survey was conducted 5 months after the extreme pollution of the 2017/2018 New Year's Eve, in order to gauge the long-term attitudes and opinions, as opposed to short-term impressions of the event. While pollution exceeds health safety limits, on average, every other New Year's Eve in the capital of Iceland [26], this particular year was unique, not only 
in the excessive pollution but also in the extensive media coverage on the imminent pollution and its effect on the environment and health. Not only did environmental and health authorities issue warnings, but scientists and doctors also urged the public to show constraint in purchasing fireworks.

\subsection{Measures}

The online survey consisted of 9 single-item measures (Table 1), as well as the background questions. The single items were intended to measure purchasing behavior, hedonic motives, awareness of the harm of fireworks, acceptance of governmental mitigating actions, and charitable motives. The statements were developed based on (a) general views proclaimed in informal sources, such as news articles in local media and multimedia discussions before and after the 2017/2018 New Year's Eve, and (b) local stakeholder opinions and conflicts regarding whether fireworks were purchased to fund a charity or to have fun, for example [26]. The statements were presented in a semi-random order and were answered with a five-point Likert scale-from "strongly disagree" (1) to "strongly agree" (5) - with the options to respond "does not apply", "do not know", or "do not wish to answer". Higher numbers thus denote more agreement with the statements (Table 1).

Table 1. Descriptive statistics of measures used in the analyses.

\begin{tabular}{|c|c|c|c|}
\hline & Constructs and Measures & $\% 1$ & $M(S D)$ \\
\hline \multicolumn{4}{|l|}{ Purchase behavior } \\
\hline & 1. I usually buy fireworks & 51.4 & $3.10(1.65)$ \\
\hline \multicolumn{4}{|l|}{ Hedonic motives } \\
\hline & 2. I enjoy igniting fireworks (active) & 44.5 & $2.92(1.46)$ \\
\hline & 3. I enjoy watching fireworks (passive) & 80.5 & $4.13(1.07)$ \\
\hline \multicolumn{4}{|l|}{ Awareness } \\
\hline & 4. I believe fireworks are harmful to health & 69.0 & $3.95(1.12)$ \\
\hline & $\begin{array}{l}\text { 5. I noticed warnings of particulate matter } \\
\text { pollution due to fireworks last New Year's Eve }\end{array}$ & 70.7 & $3.91(1.28)$ \\
\hline \multicolumn{4}{|l|}{ Willingness to act } \\
\hline & 6. Public use should be banned & 27.0 & $2.48(1.46)$ \\
\hline & 7. Policy should be stricter & 56.6 & $3.57(1.38)$ \\
\hline & 8. I would buy less if warned about... & 35.6 & $3.01(1.41)$ \\
\hline \multicolumn{4}{|l|}{ Charitable motives } \\
\hline & 9. I mostly buy from Ice-SAR & 85.7 & $4.39(1.11)$ \\
\hline
\end{tabular}

$1 \%=$ Percentage of respondents who agree or strongly agree with the statement (nation weighted)

Purchasing behavior was assessed with the question "I usually purchase fireworks around New Year's".

Hedonic motives were defined simply as the enjoyment of fireworks and were assessed via two items measuring active participation ("I enjoy igniting fireworks") as well as passive participation ("I enjoy watching fireworks").

Awareness was measured with two statements: "I believe that firework pollution can harm health" assesses the belief in the harmfulness of pollution to the individual; "I noticed warnings of particulate pollution last New Year's Eve" assesses both the awareness of the severity of the environmental pollution, which was widely covered in the news prior and after the event, and the effectiveness of the mitigation method currently employed by the local environmental health authorities, which is to issue warnings if the pollution is expected to exceed health safety limits.

Charitable motives. Despite there being numerous possible reasons (e.g., ease of access) for choosing to purchase from Ice-SAR, we know from media and stakeholder interviews [26] that people claim there are charitable motives behind buying their fireworks from Ice-SAR. Therefore, we decided to use 
the statement "I buy fireworks first and foremost from Ice-SAR" as our proxy measure of charitable motives. This measure is the best approximation in our dataset to gauge the norm that one should engage in socially conscious, altruistic consumption by funding Ice-SAR. Other retailers sell fireworks at better prices and for their own gain. Therefore, people purchase from Ice-SAR at a premium price because they are conscious of the importance of this source of fundraising [26].

Willingness to act. The acceptance of three different possible actions that mitigate pollution was tested. Support for the currently employed policy, placing the responsibility to heed warnings and reduce purchasing on the individual, was tested with the statement "I would buy fewer fireworks if health authorities warned about particulate matter pollution". The public acceptance of a tighter policy was tested with "Government should enforce stricter regulations on fireworks use around New Year's". Lastly, the strictest form of public restriction was tested with the statement "The public use of fireworks should be banned". This could incorporate moving towards planned firework displays as well as a full ban.

The response rate was generally $>94 \%$ per question, except in the two advanced questions on purchasing habits $(80 \%)$, which could be explained by the fact that not everyone in the sample purchases fireworks.

\subsection{Statistical Analyses}

The hypotheses were tested using hierarchical multiple regression in SPSS Statistics v26 (IBM Corp., Armonk, NY, USA). In hierarchical regression we fit increasingly complicated models to our data, checking whether each model significantly adds to the explained variance of the independent variable $\left(\Delta R^{2}\right.$ ). In all analyses, we first controlled for age, gender (using a dummy variable where male $=1$ and other $=0$ ), and education, as well as political orientation (where liberal conservatives $=1$ and other political parties $=0$ ).

Moderation analyses were run using PROCESS for SPSS v3.3. All variables, apart from demographics, were standardized prior to the analyses. An interaction between awareness (believing in the health risk from firework pollution) and egoism (mean score of two variables; enjoyment of igniting and watching fireworks) was computed using mean-centered variables.

\section{Results}

The survey questions were inter-correlated at a significant level $(p<0.001$; Table 1$)$, with notable exemptions. Charitable motives were not related to the support for mitigation, and purchasing behavior was not associated with whether people noticed government warnings. The highest positive correlations were between active participation and purchasing behavior, and the highest negative correlations were between hedonism and the support for mitigation, both supporting the literature on egoistic vs. altruistic and biospheric values.

Hypothesis 1 states that the awareness of the health risk of recreational fireworks is a weaker predictor of purchasing behavior than hedonic motives. The single order correlation between these variables provides support for the hypothesis (Table 2), but to further test the hypothesis we ran a stepwise hierarchical regression in three successive steps (final model shown): first, testing the association between the awareness of health risk and purchasing behavior; afterwards, controlling for background variables; and then entering both variables assessing hedonic motives in the final model, shown in Table 3. As predicted, hedonic motives-and, in particular, active participation $(\beta=0.59 ; p<0.001)$ - are the main drivers behind the purchase of fireworks for NYE celebrations in Iceland, supporting Hypothesis 1 (Table 3). All models were significant predictors of purchasing behavior, but Model $3(F(8,643)=67.262 ; p<0.001)$ added $34 \%$ to the explained variance of purchasing behavior, thus accounting for a total of $46 \%$ in variation. The single largest significant predictor was the enjoyment of igniting fireworks. 
Table 2. Correlations between the tested measures.

\begin{tabular}{|c|c|c|c|c|c|c|c|c|c|c|c|c|}
\hline Measures & 1. & 2. & 3. & 4. & 5. & 6. & 7. & 8. & 9. & 10. & 11. & 12 \\
\hline \multicolumn{13}{|l|}{ 1. Gender } \\
\hline 2. Age & 0.05 & & & & & & & & & & & \\
\hline 3. Education & $-0.08 *$ & $-0.16^{* * *}$ & & & & & & & & & & \\
\hline 4. Vote conservative & $0.14^{* * *}$ & 0.07 & -0.00 & & & & & & & & & \\
\hline 5. Purchase behavior & $0.18^{* * *}$ & $-0.09 *$ & -0.06 & $0.08 *$ & - & & & & & & & \\
\hline 6. Hedonic motive-enjoy igniting & $0.29 * * *$ & $-0.10^{* *}$ & $-0.10 * *$ & $0.08 *$ & $0.67^{* * *}$ & - & & & & & & \\
\hline 7. Hedonic motive-enjoy watching & 0.03 & -0.07 & -0.05 & 0.05 & $0.43^{* * *}$ & $0.51^{* * *}$ & - & & & & & \\
\hline 8. Awareness-belief in harm & $-0.13^{* * *}$ & 0.05 & $0.20^{* * *}$ & $-0.17^{* * *}$ & $-0.29 * * *$ & $-0.32 * * *$ & $-0.25^{* * *}$ & - & & & & \\
\hline 9. Awareness-noticed warnings & -0.00 & $0.15^{* * *}$ & $0.09 *$ & -0.01 & -0.01 & -0.05 & -0.01 & $0.30 * * *$ & - & & & \\
\hline 10. Willingness to act- - public ban & $-0.18^{* * *}$ & 0.05 & $0.10^{* *}$ & $-0.14^{* * *}$ & $-0.39 * * *$ & $-0.46^{* * *}$ & $-0.45^{* * *}$ & $0.50 * * *$ & $0.22 * * *$ & - & & \\
\hline 11. Willingness to act-restrict & $-0.23 * * *$ & $0.11 * *$ & 0.12 ** & $-0.14^{* * *}$ & $-0.37^{* * *}$ & $-0.40 * * *$ & $-0.31 * * *$ & $0.62 * * *$ & $0.25^{* * *}$ & $0.64^{* * *}$ & - & \\
\hline 12. Willingness to act-heed warnings & $-0.18^{* * *}$ & 0.01 & $0.18^{* * *}$ & $-0.12 * *$ & $-0.14^{* * *}$ & $-0.23^{* * *}$ & $-0.18^{* * *}$ & $0.48^{* * *}$ & $0.21 * * *$ & $0.46^{* * *}$ & $0.56^{* * *}$ & - \\
\hline 13. Charitable motive-Ice-SAR & -0.03 & $-0.11^{* *}$ & 0.07 & $-0.15^{* * *}$ & $0.29 * * *$ & $0.18^{* * *}$ & $0.24 * * *$ & -0.06 & 0.03 & $-0.10 *$ & -0.01 & 0.05 \\
\hline
\end{tabular}


Table 3. Hierarchical regression predicting the habitual purchasing of fireworks, Model 3.

\begin{tabular}{ccc}
\hline Measures & $\boldsymbol{B}(\mathrm{SE})$ & $\boldsymbol{\beta}$ \\
\hline Gender $(1=$ male $)$ & $0.01(0.10)$ & 0.00 \\
Age & $-0.01(0.03)$ & -0.01 \\
Education & $0.03(0.04)$ & 0.02 \\
Vote conservative (=1) & $0.10(0.12)$ & 0.03 \\
\hline Awareness-belief in harm & $-0.12(0.05)$ & $-0.08^{*}$ \\
Awareness-noticed warnings & $0.02(0.04)$ & 0.02 \\
Hedonic motive-enjoy igniting & $0.66(0.04)$ & $0.59 * * *$ \\
Hedonic motive-enjoy watching & $0.14(0.05)$ & $0.09{ }^{* *}$ \\
\hline${ }^{*} p<0.05 ;{ }^{* *} p<0.01 ;{ }^{* * *} p<0.001$. &
\end{tabular}

In Hypothesis 2 we propose that hedonic motives (enjoyment of igniting and watching fireworks) are negatively related with the acceptance of mitigating actions, a general ban of fireworks (Hypothesis $2 \mathrm{a})$, stricter regulations (Hypothesis $2 \mathrm{~b}$ ), and the intention to heed warnings (Hypothesis 2c). To test this, we ran three hierarchical regressions, controlling for background in the first step and awareness of the harmful effects of recreational fireworks in the second, before adding hedonic motives in the third step and an interaction term in the final step. Table 4 shows the fourth and final model. Hypotheses $2 \mathrm{a}$ and $2 \mathrm{~b}$ are supported. Hedonic motives add significantly, albeit modestly, to the explained variance and are negatively related with the acceptance of a ban and stricter regulations, but are not related to the intention to heed warnings (Hypothesis 2c).

Table 4. Hierarchical regression for three models predicting support for willingness to act.

\begin{tabular}{ccccccc}
\hline & \multicolumn{2}{c}{ H2a: Ban } & \multicolumn{2}{c}{ H2b: Restrict } & \multicolumn{2}{c}{ H2c: Warn } \\
\hline Measures & B(SE) & $\boldsymbol{\beta}$ & $\boldsymbol{B}($ SE) & $\boldsymbol{\beta}$ & $\boldsymbol{B}($ SE) & $\boldsymbol{\beta}$ \\
\hline$a$ & $0.20(0.18)$ & & $0.00(0.17)$ & & $0.10(0.21)$ & \\
Gender (1=male) & $-0.25(0.09)$ & $-0.08^{* *}$ & $-0.33(0.08)$ & $-0.12^{* * *}$ & $-0.35(0.11)$ & $-0.12^{* *}$ \\
Age & $-0.03(0.03)$ & -0.04 & $0.05(0.03)$ & $0.06^{+}$ & $0.01(0.03)$ & 0.01 \\
Education & $0.00(0.03)$ & 0.00 & $-0.01(0.03)$ & -0.01 & $0.08(0.04)$ & $0.07^{+}$ \\
Vote conservative (=1) & $-0.20(0.11)$ & $-0.06^{+}$ & $-0.15(0.10)$ & -0.04 & $-0.18(0.12)$ & -0.05 \\
\hline Awareness-belief in harm & $0.43(0.04)$ & $0.34^{* * *}$ & $0.63(0.04)$ & $0.52^{* * *}$ & $0.47(0.05)$ & $0.39^{* * *}$ \\
Awareness-noticed warnings & $0.12(0.04)$ & $0.11^{* *}$ & $0.09(0.03)$ & $0.08^{* *}$ & $0.12(0.04)$ & $0.11^{* *}$ \\
Hedonic motive-enjoy igniting & $-0.20(0.04)$ & $-0.20^{* * *}$ & $-0.13(0.03)$ & $-0.13^{* *}$ & $-0.03(0.04)$ & -0.03 \\
Hedonic motive-enjoy watching & $-0.32(0.05)$ & $-0.24^{* * *}$ & $-0.13(0.05)$ & $-0.10^{* *}$ & $-0.10(0.06)$ & -0.07 \\
Awareness x hedonism & $-0.09(0.04)$ & $-0.08^{* *}$ & $0.01(0.03)$ & 0.01 & $0.07(0.04)$ & 0.06 \\
\hline
\end{tabular}

For all three hypotheses ( $2 a, b$, and $c)$, the third steps, including the hedonic motives, were significant. With regard to the banning of fireworks, the third step accounted for a total of $42.0 \%$ of the total variance of supporting a general ban on fireworks. The model was significant $(F(8,681)=60.958 ; p<0.001)$ and the largest predictor for supporting a ban on fireworks was believing in the health risk of firework pollution. This was also the single largest predictor for the support for a stricter governmental policy on the public access to fireworks. That model accounted for $46.8 \%$ of the total variance of support for a stricter policy and was significant $(F(8,685)=74.560 ; p<0.001)$. Finally, the third step accounted for $29.4 \%$ of the explained variance of the intention to purchase fewer fireworks if warned $(F(8,596)=30.621 ; p<0.001)$, and, again, the largest predictor of the intention to purchase fewer fireworks was the awareness of the health risk. Consistently, men are less accepting of mitigating action against firework pollution.

Hypothesis 3 states that hedonic motives moderate the association between the awareness of the health risks of firework pollution and the willingness to accept a general ban on fireworks (Hypothesis 3a), stricter regulations (Hypothesis 3b), and the intention to heed warnings (Hypothesis 3c). The final row in Table 4 shows the results of our tests of these hypotheses. Hypothesis $3 a$ is supported: the interaction term between the awareness of the health risk and the enjoyment of fireworks predicting the support 
for a ban on the public use of fireworks is significant. Hypotheses $3 b$ and $3 c$ are not supported: hedonic motives do not moderate the association between awareness and the support for stricter regulations and the willingness to purchase fewer fireworks if warned.

To further examine the significant interaction, simple effects were analyzed with a moderation analysis using the Process procedure for SPSS v3.3. First, we entered the support for a ban as an outcome variable, the awareness of the health risk as the predictor variable, and hedonism as the moderator variable, controlling for right-wing politics, age, gender, and education. The overall model was significant $\left(F(7,704)=60.93 ; p<0.001 ; R^{2}=0.38\right)$. The interaction between hedonic motives and the awareness of the health risk was significant $(b=-0.075 ; t=-2.88 ; p<0.05)$. Table 5 shows the coefficients for the association between the support for a ban and the awareness of the health risk for high, medium, and low levels of hedonic motives. The results show that hedonic motives moderate the strength of the association between the awareness of the health risks and the acceptance of banning fireworks. When hedonism is high, the association between the awareness of the health risks of firework pollution and the acceptance of a ban is weaker than when hedonism is low.

Table 5. Effects analysis results for the interaction of the awareness of the health risk $\mathrm{x}$ hedonic motives on the support for a ban on the public use of fireworks.

\begin{tabular}{lccccc}
\hline \multicolumn{1}{c}{ Support for Ban at } & $\boldsymbol{a}$ & $\boldsymbol{B}(\mathrm{SE})$ & $\boldsymbol{B}$ 95\% CI $[\mathbf{L L}, \boldsymbol{U L}]$ & $\boldsymbol{t}$ & $\boldsymbol{p}$ \\
\hline low hedonism & -1.47 & $0.63(0.06)$ & {$[0.50,0.74]$} & 10.69 & 0.000 \\
medium hedonism & 0.00 & $0.53(0.04)$ & {$[0.43,0.59]$} & 13.26 & 0.000 \\
high hedonism & 1.47 & $0.43(0.05)$ & {$[0.30,0.50]$} & 8.61 & 0.000 \\
\hline
\end{tabular}

Finally, the fourth hypothesis states that charitable motives (purchasing from Ice-SAR) is a weaker predictor of purchasing behavior than hedonic motives (enjoying igniting and watching fireworks). This hypothesis is supported (Table 6): hedonic motives are by far a stronger predictor of purchasing behavior than purchasing to support Ice-SAR ( $\beta=0.58$ vs. 0.17 ) and add significantly $34 \%$ to the explained variance. The total $R^{2}$ for the final model is 0.48 , and the model is $\operatorname{significant}(F(7,646)=84.99$; $p<0.001)$.

Table 6. Hierarchical regression coefficients, standard errors, and changes in the explained variance for predicting purchasing behavior from hedonic and charitable motives.

\begin{tabular}{|c|c|c|}
\hline Measures & $B(S E)$ & $\beta$ \\
\hline Gender $(1=$ male $)$ & $0.03(0.10)$ & 0.00 \\
\hline Age & $-0.01(0.03)$ & -0.01 \\
\hline Education & $-0.01(0.04)$ & -0.01 \\
\hline Vote conservative $(=1)$ & $0.24(0.12)$ & $0.06^{*}$ \\
\hline Charitable motive-mostly buy from Ice-SAR & $0.25(0.04)$ & $0.17^{* * *}$ \\
\hline Hedonic motive - enjoy igniting & $0.65(0.04)$ & $0.58^{* * *}$ \\
\hline Hedonic motive-enjoy watching & $0.15(0.05)$ & $0.09^{* *}$ \\
\hline
\end{tabular}

\section{Discussion}

Drawing on research from environmental psychology we studied whether the awareness of harmful pollutants and hedonic or charitable motives help to explain why people purchase fireworks and support or oppose mitigating action against firework pollution.

Our hypotheses were largely supported. We found that the purchase of fireworks was strongly related to hedonic motives. In addition, we found that although people are aware of the health risks posed by firework pollution, they still purchase fireworks, because of the pleasure they derive from igniting and watching them. These findings demonstrate the difficulties of relying on raising awareness to promote behavioral change. 
Our findings also show that hedonic motives predict the opposition to mitigating action. Those who enjoy igniting fireworks are, not surprisingly, less likely to accept a ban on the public use of fireworks. Although the awareness of the health risk of firework pollution increases the support for banning fireworks, hedonic motives moderate that association by reducing the impact of awareness on the support for banning fireworks. That is, those who enjoy fireworks the most are least likely to let their knowledge of the harmful pollutants affect their stance on a ban. However, counter to our predictions, we found that hedonic motives have a weak association with the opposition to (a) stricter firework regulation or (b) the intention to purchase fewer fireworks if warned about their health risk. The awareness of the health risk posed by firework pollution was by far the strongest predictor of the support for stricter regulations, which may imply an ambivalence: although people enjoy fireworks, they want this matter out of their hands, and may want to be protected from their guilty pleasures.

Finally, our results showed that hedonic motives were a stronger predictor of purchase behavior than charitable motives. We acknowledge that our measure of altruistic or charitable motives is a weak point in our research, but we find the conflict inherent to the socially responsible consumption of a polluting substance too interesting to ignore. Our results on this issue should be interpreted with care, and future research should include appropriate measures.

Our limited measures only give an indication of how awareness and motives influence firework purchase and the support for mitigation against fireworks. Although the prime strength of our study is the nationally representative internet panel survey, such surveys can be expensive. Thus, we had to limit the numbers of questions. Optimally, we would have included psychometrically sound scales measuring egoistic, altruistic, and biospheric values, in order to strengthen our argument. Future research should ideally include the measurement by deGroot and Steg (2008) or Schwartz's value scale [36]. Our assessment of hedonic motives consisted of two items, asking about participants' enjoyment of both watching and igniting fireworks, and the latter was consistently a stronger predictor of both behavior and resistance to mitigation. This difference between active and passive participation in the firework extravaganza on New Year's Eve in Iceland is interesting. The people who are actively lighting up fireworks for their family and friends are more involved and therefore have a vested interest in maintaining the status quo. These people tend to be middle-aged, conservative, less educated men, as is common in research on environmentally detrimental behavior [16].

Despite lasting only a few hours or a few days, firework celebrations produce an environmental footprint comparable to weeks' or months' worth of average day pollution [26]. Yet our measure of the awareness of the polluting nature of fireworks was limited to the health consequences, and did not include the environmental consequences. This is because it is by now well known that invoking health co-benefits increases people's willingness to address environmental issues [37,38], which has been shown to affect people across the ideological divide [39]. This could be true for polluting behaviors, whether they are psychologically proximal or not. The reason for this is that people have a harder time understanding and relating to measures of atmospheric particles and gases than to measures of health and vitality. Therefore, policy makers are advised to continue to highlight the health-related co-benefits of mitigating efforts to environmental problems.

Firework usage is interesting not only in that it is extremely polluting, but also because its effects are immediate. This is contrary to most behaviors examined by environmental psychologists. However, our results align with earlier studies on values, awareness, and environmental behavior which suggests that psychological distance may perhaps be less of a barrier than previously thought, at least for hedonic activities. Most studies in environmental psychology have focused on climate change. This means that psychologically proximal environmental issues have remained understudied. More research is needed in order to verify whether our results on fireworks applies to other psychologically proximal issues. Other behaviors with similarly immediate consequences, whether socially accepted normative behaviors like fireworks or behaviors perceived to be anti-social (such as vandalizing the natural environment, littering, dumping) could be examined within this framework, considering the awareness-value-behavior gap. 
Those trying to reduce the pollution from fireworks in Iceland face two hurdles. The first is addressing the marketing of fireworks by Ice-SAR as socially conscious consumption, and providing alternative sources of funding. Placing the responsibility of funding Ice-SAR on individual consumers' conscience has been the dominant approach. Research shows that cause-related marketing increases sales despite the product being harmful [40]. The second hurdle is to convince the public that mitigating efforts are necessary. This may be easier to overcome. The ridiculousness of funding a vital organization by purchasing polluting substances used for a moment of pleasure, ironically leading to clouds of smoke so thick that they have blocked the sight of the fireworks for the past years, may be dawning on the people in our sample. Our study did show that the awareness of the health risks of firework pollution was highly related with the acceptance of stricter regulation. Future studies need to ask people whether their continued purchasing and igniting of fireworks, despite the knowledge of their harm, are driven by social norms and perceived responsibility to fund Ice-SAR, and whether or not they are willing to agree to other, more benign sources of funding. We believe our results suggest that although the public greatly enjoys engaging in fireworks, both watching them and igniting them, they realize that their immediate wants may need to be regulated. To paraphrase Jenny Holzer's expression, they wish to be protected from what they want.

Author Contributions: Conceptualization, H.Ó.A., R.B.G., and T.T.; methodology and formal analysis, R.B.G.; writing—original draft preparation, R.B.G. and H.O.A.; writing—review and editing, R.B.G., H.Ó.A., and T.T.; supervision and funding acquisition, H.Ó.A. All authors have read and agreed to the published version of the manuscript.

Funding: This research was funded by the Engineering Institute of the University of Iceland (P.I. Hrund Andradóttir).

Acknowledgments: We would like to thank the Engineering Research Institute of the University of Iceland for funding the project. We are also grateful to the Social Science Research Institute at the University of Iceland and Margrét Sigrún Sigurðardóttir, Associate Professor in Business at the University of Iceland, for the feedback on the national poll design.

Conflicts of Interest: The authors declare no conflict of interest.

\section{References}

1. Intergovernmental Panel on Climate Change (IPCC). Global Warming of $1.5^{\circ} \mathrm{C}$ : An IPCC Special Report on the Impacts of Global Warming of $1.5^{\circ} \mathrm{C}$ above Pre-industrial Levels and Related Global Greenhouse Gas Emission Pathways, in the Context of Strengthening the Global Response to the Threat of Climate Change, Sustainable Development, and Efforts to Eradicate Poverty; Masson-Delmotte, V., Zhai, P., Pörtner, H.O., Roberts, D., Skea, J., Shukla, P.R., Pirani, A., Moufouma-Okia, W., Péan, C., Pidcock, R., et al., Eds.; IPCC: Geneva, Switzerland, 2018.

2. Vitousek, P.M.; Mooney, H.A.; Lubchenco, J.; Melillo, J.M. Human domination of earth's ecosystems. Science 1997, 277, 494-499. [CrossRef]

3. Wackernagel, M.; Niels, B.; Schulz, N.B.; Deumling, D.; Linares, A.C.; Jenkins, M.; Kapos, V.; Monfreda, C.; Loh, J; Myers, N.; et al. Tracking the ecological overshoot of the human economy. Proc. Natl. Acad. Sci. USA 2002, 99, 9266-9271. [CrossRef]

4. Kollmuss, A.; Aygeman, J. Mind the gap: Why do people act environmentally and what are the barriers to pro-environmental behavior? Environ. Educ. Res. 2002, 8, 239-260. [CrossRef]

5. Kaplan, B.; Reed, D.; McKerchar, T. Using a visual analogue scale to assess delay, social, and probability discounting of an environmental loss. Psychol. Record. 2014, 64, 261-269. [CrossRef]

6. Amel, E.; Manning, C.; Scott, B.; Kogel, S. Beyond the roots of human inaction: Fostering collective effort toward ecosystem conservation. Science 2017, 356, 275-279. [CrossRef] [PubMed]

7. Gifford, R. The dragons of inaction: Psychological barriers that limit climate change mitigation and adaptation. Am. Psychol. 2011, 66, 290-302. [CrossRef]

8. Lorenzoni, I.; Nicholson-Cole, S.; Whitmarsh, L. Barriers perceived to engaging with climate change among the UK public and their policy implications. Glob. Environ. Chang. 2007, 17, 445-459. [CrossRef]

9. Lacroix, K.; Gifford, R. Psychological barriers to energy conservation behavior: The role of worldviews and climate change risk perception. Environ. Behav. 2018, 50, 749-780. [CrossRef] 
10. Schwartz, S.H.; Cieciuch, J.; Vecchione, M.; Davidov, E.; Fischer, R.; Beierlein, C.; Ramos, A.; Verkasalo, M.; Lönnqvist, J.-E.; Demirutku, K.; et al. Refining the theory of basic individual values. J. Pers. Soc. Psychol. 2012, 103, 663-688. [CrossRef]

11. Verplanken, B.; Holland, R.W. Motivated decision making: Effects of activation and self-centrality of values on choices and behavior. J. Pers. Soc. Psychol. 2002, 82, 434-447. [CrossRef]

12. Bardi, A.; Schwartz, S.H. Values and behavior: Strength and structure of relations. Pers. Soc. Psychol. B 2003, 29, 1207-1220. [CrossRef]

13. De Groot, J.; Steg, L. Value orientations and environmental beliefs in five countries: Validity of an instrument to measure egoistic, altruistic and biospheric value orientations. J. Cross Cult. Psychol. 2008, 38, 318-332. [CrossRef]

14. Steg, L.; Dreijerink, L.; Abrahamse, W. Factors influencing the acceptability of energy policies: Testing VBN theory. J. Environ. Psychol. 2005, 25, 415-425. [CrossRef]

15. Stern, P.C. Toward a coherent theory of environmentally significant behavior. J. Soc. Issues 2000, 56, 407-424. [CrossRef]

16. Davidson, D.J.; Haan, M. Gender, political ideology, and climate change beliefs in an Extractive Industry Community. Popul. Environ. 2012, 34, 217-234. [CrossRef]

17. Feygina, I.; Jost, J.T.; Goldsmith, R.E. System justification, the denial of global warming, and the possibility of 'system-sanctioned change'. Pers. Soc. Psychol. B 2010, 36, 326-338. [CrossRef]

18. McCright, A.M.; Dunlap, R.E. Cool dudes: The denial of climate change among conservative white males in the United States. Glob. Environ. Chang. 2011, 21, 1163-1172. [CrossRef]

19. Whitmarsh, L. Scepticism and uncertainty about climate change: Dimensions, determinants and change over time. Glob. Environ. Chang. 2011, 21, 690-700. [CrossRef]

20. Thøgersen, J.B. Norms for environmentally responsible behavior: An extended taxonomy. J. Environ. Psychol. 2006, 26, 247-261. [CrossRef]

21. Jones, C.; Hine, D.; Marks, A.D.G. The future is now: Reducing psychological distance to increase public engagement with climate change. Risk Anal. 2017, 37, 331-341. [CrossRef]

22. Sargisson, R.J.; Schöner, B.V. Hyperbolic discounting with environmental outcomes across time, space, and probability. Psychol. Rec. 2020. [CrossRef]

23. Griffioen, A.M.; van Beek, J.; Lindhout, S.N.; Handgraaf, M.J.J. Distance makes the mind grow broader: An overview of psychological distance studies in the environmental and health domains. APSTRACT 2016, 10, 33-46. [CrossRef] [PubMed]

24. Ji, D.S.; Cui, Y.; Li, L.; He, J.; Wang, L.L.; Zhang, H.L.; Wang, W.; Zhou, L.X.; Maenhaut, W.; Wen, T.X.; et al. Characterization and source identification of fine particulate matter in urban Beijing during the 2015 Spring Festival. Sci. Tot. Environ. 2018, 628-629, 430-440. [CrossRef] [PubMed]

25. Kumar, M.; Singh, R.K.; Murari, V.; Singh, A.K.; Singh, R.S.; Banerjee, T. Fireworks induced particle pollution: A spatio-temporal analysis. Atmos. Res. 2016, 180. [CrossRef]

26. Andradóttir, H.O.; Thorsteinsson, T. Repeated extreme particulate matter episodes due to fireworks in Iceland and stakeholders' response. J. Clean. Prod. 2019, 236, 117511. [CrossRef]

27. Hamad, S.; Green, D.; Heo, J. Evaluation of health risk associated with fireworks activity at Central London. Air Qual. Atmos. Health 2016, 9, 735-741. [CrossRef]

28. Greven, F.E.; Vonk, J.M.; Fischer, P.; Duijm, F.; Vink, N.M.; Brunekreef, B. Air pollution during New Year's fireworks and daily mortality in the Netherlands. Sci. Rep. 2019, 9, 5735. [CrossRef]

29. Seidel, D.J.; Birnbaum, A.N. Effects of Independence Day fireworks on atmospheric concentrations of fine particulate matter in the United States. Atmos. Environ. 2015, 115, 192-198. [CrossRef]

30. Gudmundsson, G.; Andradottir, H.O.; Thorsteinsson, T. Fireworks pollution and its impacts on pulmonary health of Icelanders (In Icelandic: Mengun af völdum flugelda og ahrif a lungnaheilsu Islendinga). Læknabladid 2018, 104, 576-577.

31. Peshin, S.K.; Sinha, P.; Bisht, A. Impact of Diwali firework emissions on air quality of New Delhi, India during 2013-2015. Mausam 2017, 68, 111-118.

32. Lai, Y.H.; Brimblecombe, P. Regulatory effects on particulate pollution in the early hours of Chinese New Year, 2015. Environ. Monit. Assess 2017, 189, 467. [CrossRef] [PubMed]

33. Ye, C.; Chen, R.S.; Chen, M.X. The impacts of Chinese Nian culture on air pollution. J. Clean. Prod. 2016, 112, 1740-1745. [CrossRef] 
34. Licudine, J.A.; Yee, H.; Chang, W.L.; Whelen, A.C. Hazardous metals in ambient air due to new year fireworks during 2004-2011 celebrations in Pearl City, Hawaii. Public Health Rep. 2012, 127, 440-450. [CrossRef] [PubMed]

35. Directive 2013/29/EU of 12 June 2013 on the Harmonization of the Laws of the Member States Relating to the Making Available on the Market of Pyrotechnic Articles. Available online: https://eur-lex.europa.eu/ LexUriServ/LexUriServ.do?uri=OJ:L:2013:178:0027:0065:en:PDF (accessed on 26 June 2020).

36. McQuilkin, J.V.; Garðarsdóttir, R.B.; Thorsteinsson, T. Schwartz, S. An Icelandic translation and validation of the revised 19-value Portrait Values Questionnaire. Pers. Indiv. Differ. 2016, 101, 428-434. [CrossRef]

37. Thurston, G.D. Mitigation policy: Health co-benefits. Nat. Clim. Chang. 2013, 3, 863-864. [CrossRef]

38. Amelung, D.; Fischer, H.; Herrmann, A.; Aall, C.; Louis, V.R.; Becher, H.; Wilkinson, P.; Sauerborn, R. Human health as a motivator for climate change mitigation: Results from four European high-income countries. Glob. Environ. Chang. 2019, 57. [CrossRef]

39. Bain, P.G.; Milfont, T.L.; Kashima, Y.; Bilewicz, M.; Doron, G.; Garðarsdóttir, R.B.; Gouveia, V.V.; Guan, Y.; Johansson, L.O.; Pasquali, C.; et al. Co-benefits of addressing climate change can motivate action around the world. Nat. Clim. Chang. 2015, 6, 154-157. [CrossRef]

40. Grolleau, G.; Ibanez, L.; Lavoie, N. Cause-related marketing of products with a negative externality. J. Bus. Res. 2016, 69, 4321-4330. [CrossRef]

(C) 2020 by the authors. Licensee MDPI, Basel, Switzerland. This article is an open access article distributed under the terms and conditions of the Creative Commons Attribution (CC BY) license (http://creativecommons.org/licenses/by/4.0/). 